\title{
Discurso jurídico y cultura legal: jugadores y tahúres frente al control policial en Manizales, Colombia (1855-1874)*
}

\author{
Juridical Speech and Legal Culture: Gamblers and Tahúres \\ against Police Control in Manizales, Colombia (1855-1874)
}

\author{
Edwin Andrés Monsalvo Mendoza \\ Universidad de Caldas \\ Manizales, Colombia \\ edwin.monsalvo@ucaldas.edu.co \\ Héctor Miguel López Castrillón \\ Universidad Autónoma de Manizales \\ Manizales, Colombia \\ hectorm.lopezc@autonoma.edu.co
}

\section{Resumen}

El objetivo de este artículo es mostrar cómo en las disputas judiciales entre alcaldes locales y practicantes de juegos de azar se dio una circulación de la información

\footnotetext{
"Este trabajo hace parte del proyecto de investigación titulado "La justicia local y la construcción del orden de policía. El control social en Manizales 1850-1900", el cual cuenta con la financiación de la Vicerrectoría de Investigaciones y Posgrados de la Universidad de Caldas (código I-VIP-TD-008-convocatoria 2017).
}

Cómo citar este artículo/ How to cite this article: Monsalvo Mendoza, E. A. y López Castrillón, H. M.. (2021). Discurso jurídico y cultura legal: jugadores y tahúres frene al control policial en Manizales, Colombia, (1855-1874). Revista de Historia Americana y Argentina, 56 (1), pp. 203-234. https://doi.org/10.48162/rev.44.006 
jurídica y procesal que fue consolidando una cultura legal en los sectores populares y en los agentes estatales encargados del orden. La metodología se basa en el análisis crítico de una tipología documental compuesta de expedientes sumariales, códigos de policía y cuadernos de apelación, examinados desde la perspectiva de la historia social de las formas de control. Al final, se presenta a modo de resultados las estrategias empleadas por los judiciables para obstaculizar los juicios, así como las herramientas por dentro y fuera de la norma que emplearon los jefes de policía para hacer frente a estos intentos. Se concluye que en esta dicotomía entre alcaldes y jugadores emergió un debate de ideas que obligó a unos y otros a perfeccionar su conocimiento sobre los procedimientos judiciales.

Palabras clave: alcaldes parroquiales, juegos de azar prohibidos, orden de policía, discurso jurídico, cultura legal.

\begin{abstract}
The purpose of this article is to show how in the legal disputes between local mayors and gambling practitioners, there was a circulation of legal and procedural information that consolidated a legal culture between popular sectors and state agents in charge of order. The methodology is based on a critical analysis of a documentary typology of summary files, police codes and appeal notebooks; examined from the perspective of social history forms of control. At the end, the strategies used by the prosecutors to hinder trials are presented as results, also the tools, inside and outside the law, that police chiefs used to face these attempts. It is concluded that on this dichotomy between mayors and players, a debate of ideas emerged forcing them to improve their judicial procedures knowledge.
\end{abstract}

Key words: parish mayors, gambling games, police order, legal discourse, legal culture.

Recibido: 27/04/2020 Aprobado: 20/11/2020

\title{
Introducción
}

Durante las décadas de los años cincuenta y sesenta de la centuria decimonónica, los alcaldes de Manizales fueron escogidos por los cabildos parroquiales dentro de las élites locales (Giraldo, 2012). Muchos de ellos escasamente sabían leer y escribir, pero debieron reconocer y aprehender 
de leyes para enfrentar a los infractores que juzgarían de acuerdo a los códigos de la época ${ }^{1}$. Con poco capital cultural, estos hombres estuvieron encargados de mantener el orden de policía, para lo cual debieron mitigar las consecuencias morales y económicas de prácticas como los juegos de azar que eran prohibidos ${ }^{2}$. Esto es, evitar que pulularan vagos y delincuentes al tiempo que protegían un ideal social de hombre honrado, trabajador y responsable de su prole. De esta forma, los alcaldes se vieron enfrentados a prostitutas, jugadores, ladrones, contrabandistas, amancebados y toda una gama de prácticas consideradas desde los códigos de policía como contravenciones.

Según Becerra (2010), a partir de la Ley 8 de 1841 se definió el estatus y las funciones de la policía como institución, otorgando la dirección Nacional al presidente de la República, al tiempo que puso bajo la subordinación de las autoridades locales a la policía que se encontraba en las gobernaciones, los cantones y los distritos parroquiales (p. 149). Dicha norma representó un punto de quiebre en la historia de la policía colombiana, ya que estableció una relación directa entre el ejercicio de la administración pública y la labor policial, convirtiendo los alcaldes en los rostros visibles de la autoridad estatal en aquellas zonas donde aparentemente había carencia de instancias de control. Dentro de sus funciones estaba la prevención, vigilancia y castigo de algunos juegos de azar como las cartas y los dados.

En su mayoría quienes se vieron expuestos a ser vigilados por la policía, fueron campesinos que invertían su dinero y tiempo en los juegos de azar. Y aunque muchos eran analfabetos, no eran ingenuos y con la misma astucia que buscaban no ser descubiertos se defendieron cuando debieron afrontar la justicia cara a cara. En esos debates entre alcaldes, procuradores, infractores y leguleyos, se hizo evidente una circulación del conocimiento jurídico que obligó a unos y otros a perfeccionar su entendimiento de los procedimientos judiciales ${ }^{3}$. Esta concepción del problema tiene fundamento

\footnotetext{
${ }^{1}$ Sobre las dificultades de los primeros alcaldes para ejercer sus funciones, ver: Monsalvo y Bedoya, 2014, pp.41-65.

${ }^{2}$ Para entender la relación entre juegos de azar, moral y economía, ver: Whipple, 2009, pp. 1-35.

${ }^{3}$ Acerca del papel de los jueces y abogados como divulgadores de la legislación y constructores de una cultura jurídica, se recomienda ver Palacio (2004) quien plantea que: "Fruto del sistema, estos abogados se ubicaron en el medio de una demanda creciente de justicia y una oferta escasa de "ley" y desde allí hicieron su
} 
en la tesis de la apropiación social de los saberes especializados, sostenida por Bohoslavsky y Di Liscia (2005), quienes señalaron que: "No está de más recordar que los saberes especializados, que durante algún tiempo se creyeron exclusivos de las élites, escapaban de los estrechos círculos de "notables" y "científicos" en los que fueron producidos". Dichos saberes se incorporaron a la cultura popular mediante "intrincados procesos sociales y comunicativos" que permitieron que sectores subalternos se apropiaran y usaran a su favor los discursos criminológicos o psiquiátricos (p. 11).

En este escenario se ubica el presente artículo que busca identificar los elementos de dicho debate como una manera de evidenciar la difusión de la información jurídica y procesal, que permitió ir consolidando una cultura legal en el mundo rural del sur antioqueño. La noción de cultura legal

(...) hace referencia a la manera en que se vive la ley en diferentes espacios y por diferentes actores, entendiendo en este caso al sustantivo vive en un sentido amplio, como práctica, como símbolo, como significados, como tradiciones, como creencias, como concepciones, como institución, como profesión etc. (Ansolabehere, 2011-2012, p. 134).

De esta manera, la cultura legal deja de ser empleada como un concepto y se utiliza como enfoque del que se valen los diferentes actores sociales para aprehender el concepto de derecho en un momento dado y en relación con una sociedad concreta ${ }^{4}$. Específicamente, en este trabajo se exploran

agosto. En el camino, aun sin quererlo, jugaron un papel decisivo en la difusión de la información -legal, pero también, fundamentalmente, jurídica y procesal- en toda la campana bonaerense y ayudaron a consolidar a través de los años una sólida cultura legal que, gracias a ellos, también alcanzó a los sectores de más baja extracción social, cultural y económica" (p.263).

${ }^{4}$ Otras definiciones desde un enfoque culturalista plantean que las "culturas jurídicojudiciales" se acercan a la comprensión de los "valores, discursos y el saber-hacer en instancia judicial", aquí la proximidad con Clifford Geertz es más que evidente (Brangier, Díaz y Morong, 2018, pp. 75-87). Otras tienen un enfoque más jurídico: "Defino la cultura judicial como aquella en la cual la resolución de conflictos entre particulares implicaba una reflexión en el espacio de los tribunales de justicia (colegiados o unipersonales) sobre asuntos especialmente delicados para el ordenamiento político y social" (González, 2012a, p. 82). En el sentido planteado por Ansolabehere (2011-2012) se encuentra también Barriera (2012a) al considerarlo como los saberes utilizados por las mujeres del bajo pueblo (p. 67). 
las estrategias discursivas ${ }^{5}$ que implementaron los encausados por juegos prohibidos para entorpecer el curso de los juicios, como apelar a la costumbre jurídica, la pobreza material, la tradición cultural, la debilidad de las leyes, la subjetividad de los jueces y los vicios de procedimiento ${ }^{6}$.

Sostenemos que estas interacciones entre actores estatales y sociales estuvieron mediadas por la circulación de argumentos sustentados en la cultura popular y en la terminología jurídica vigente, aspectos que, en algunas ocasiones, aparecen entremezclados ${ }^{7}$. Con base en lo anterior y de acuerdo a Nieto, abordar el problema planteado desde el discurso significa tener en cuenta y "penetrar en el tejido de relaciones sociales, de identidades próximas y lejanas, que se expresan en conflictos hechos visibles en las manifestaciones culturales en un momento histórico" (Nieto, 2004, p.185). De esta manera, el estudio del discurso conduce a las representaciones que se constituyen en su núcleo y la manera como se relacionan: la significación, la realidad y su imagen (Charaudeau y Maingueneau, 2005, pp. 505-506).

El período escogido es la década que va del primer juicio sumarial desplegado por la alcaldía parroquial de Manizales. Se ha tomado una sola tipología de infracción: los juegos prohibidos. La razón que explica la elección de esta es que, durante el período de estudio, fue la infracción que más sumarios produjo y la que más judiciables sancionó. En otras palabras, durante la primera década de funcionamiento de la justicia de primera instancia en Manizales, la falta que más preocupó a los alcaldes fue la práctica de los juegos prohibidos, especialmente por su carácter colectivo.

\footnotetext{
${ }^{5}$ En el plano puramente descriptivo, lo que el término discurso designa es el cuerpo coherente de categorías mediante el cual, en una situación histórica dada, los individuos aprehenden y conceptualizan la realidad (y, en particular, la realidad social) y en función de la cual desarrollan su práctica. Dicho de otro modo, un discurso es una rejilla conceptual de visibilidad, especificación y clasificación mediante la cual los individuos dotan de significado al contexto social y confieren sentido a su relación con él, mediante el cual se conciben y conforman a sí mismos como sujetos y agentes y mediante el cual, en consecuencia, regulan su práctica social. Cabrera, 2001, pp.28-46.

${ }^{6}$ Este problema de investigación ha tomado fuerza en la historiografía manizaleña en los últimos años. Un antecedente importante es: Monsalvo y López, 2014, pp.113130.

${ }^{7}$ Para entender la relación entre cultura política y sectores subalternos, ver: Joseph y Nugent, 1994.
} 
Las fuentes que utilizamos son los expedientes judiciales o sumarios de policías que eran los procesos administrativos y jurídicos ejecutoriados por los alcaldes parroquiales después de recibir una queja o denuncia por parte de cualquier vecino 0 de comprobar con los propios comisarios la contravención a la prohibición de los juegos de azar. A partir de allí, los alcaldes debían informar al señalado las pruebas en su contra e indagar por más información, así como el judiciable tenía la oportunidad de defenderse buscando testigos o pruebas que le ayudaran. Finalmente, el alcalde con base en los testimonios y pruebas, podía declarar culpable, exonerar de los cargos o suspender el proceso. Estos documentos fueron consultados en el Archivo Histórico de Manizales.

Una de las dificultades que impone este trabajo es que las fuentes fueron construidas por las autoridades locales y sus secretarios. Sin embargo, al enfocarse en los usos de la justicia y los discursos jurídicos que tanto acusados como autoridades emplearon, la mediación hegemónica puede dejar de convertirse en un inconveniente (Falcón, 2015, p.36). A pesar de ello, se procura escuchar las voces de los subordinados ya sea mediante la lectura entre líneas de los sumarios o atendiendo a las cartas y cuadernos de pruebas presentados por estos.

\section{A manera de balance historiográfico}

Los primeros estudios que desde las ciencias sociales se acercaron al fenómeno de los juegos de azar centraron su análisis en aspectos como la naturaleza lúdica de los seres humanos. Uno de los trabajos pioneros fue Huizinga (2000) quien propuso un modelo interpretativo para entender la conexión juego-cultura" diferente a la versión psico-biológica que primaba en aquel entonces. Desde la sociología surgió una respuesta a este texto que formuló un modelo para la comprensión del juego desde la "plurivocidad" que el concepto proporcionaba en sus diferentes designaciones. Frente a la perspectiva unívoca de Huizinga y a su 
desinterés por la dimensión material del juego ${ }^{8}$, Caillois (1997) propuso ampliar su concepción para tener en cuenta otros elementos (p.24).

Ambos autores ofrecieron un abanico de posibilidades metodológicas y teóricas que fueron retomadas por historiadores, sociólogos y antropólogos interesados en el estudio de las actividades lúdicas y los juegos de azar desde una perspectiva cultural (Morillas, 1990). Categorías como ocio, vida cotidiana y diversiones populares, fueron recurrentes en estos trabajos donde los juegos de azar fueron incluidos dentro de las demás diversiones.

Uno de los primeros temas desarrollados fue la relación entre juegos de azar y cultura popular en el contexto de la Monarquía Hispánica. Un argumento presente en varios de estos trabajos fue la idea de que los juegos de azar habían sido un factor transgresor del orden estamental y un liberador de las tensiones económicas, sociales, políticas y culturales del Antiguo Régimen (Pereira, 1947).

Desde la década de 1960 resurgió un interés en algunos países de América Latina por la influencia de las ideas ilustradas. Especialmente, se debatió la tesis del "relajamiento de las costumbres" que amplió el campo de indagación acerca de las diversiones populares durante la época colonial e influenció los primeros trabajos en torno a la prohibición de los juegos de azar. Miranda (1962) pionero en este debate, sostuvo que se dieron grandes cambios económicos, sociales y culturales en la vida urbana novohispana que llevaron al afrancesamiento de las élites y a la circulación generalizada de sus ideas hacia el resto de la sociedad, provocando la proliferación de una serie de excesos (bailes, borracheras, prostitución, fiestas, juegos de azar) que fueron vistos como "pecados públicos". Sin embargo, este planteamiento fue objeto de muchas críticas ya que Miranda omitió el cambio de actitud del mismo Estado por las reformas borbónicas y desconoció el hecho de que antes, durante y después del siglo XVIII, los "excesos" estuvieron presentes en la cultura popular. En esta lógica, se consideraba que la novedad no estuvo en el "libertinaje" de los sectores populares sino en las transformaciones del mismo Estado.

${ }^{8}$ Para Huizinga, el juego es: "una acción u ocupación libre, que se desarrolla dentro de unos límites temporales y espaciales determinados, según reglas absolutamente obligatorias, aunque libremente aceptadas, acción que tiene su fin en sí misma y va acompañada de un sentimiento de tensión y alegría y de la conciencia de "ser de otro modo" que en la vida corriente". Huizinga, 2000, pp. 43-44. 
Esta forma de abordar la cultura de los sectores populares convirtió a los actores sociales en un conjunto moldeable para las elites afrancesadas que no en todos los casos tuvieron una actitud negativa frente a las diversiones. Esto fue demostrado por Viqueira (1987) quien sostuvo que durante la segunda mitad del siglo XVIII se dio un progresivo rechazo de las elites ilustradas por el resto de la sociedad y que el Estado borbónico trató de desplazar a la muchedumbre de los espacios públicos, mediante la represión de sus "comportamientos espontáneos" (p.269). Sus aportes fueron fundamentales en varios trabajos realizados en la década de 1990 así su objeto de estudio no hayan sido los juegos de apuesta como tal (Lozano, 1991, p.57).

Otro tópico identificable en una historiografía más reciente es la relación entre juegos de azar y vida cotidiana. Estas reflexiones, igual que las anteriores, abordaron la temática junto a otras como las fiestas, ceremonias, romerías y bailes. Los trabajos acerca de la vida cotidiana, también han aportado al conocimiento de los juegos como parte de la vida en sociedad (Vargas, 1990).

Otras temáticas que empezaron a ser desarrolladas desde finales del siglo $\mathrm{XX}$ fueron la relación de los juegos de azar con la modernización de América Latina y las tensiones entre policías, agentes estatales y actores marginales luego de las independencias. Se enfatizaron, en particular, las narrativas policiales, la normativa, resistencias y relaciones entre autoridades. Vélez (2010) y Cecchi (2010) mostraron que los procesos "civilizatorios" de las elites criollas buscaron combatir los "vicios" coloniales y el papel que jugó la opinión pública en difusión de la moral y la disminución de los derechos civiles.

Uno de los avances más significativos se ha dado en el estudio de los actores sociales como los jugadores, tahúres, vagos, empleados públicos, militares, clérigos, comerciantes y empresarios. En esta tendencia se han estudiado los lugares de juego clandestino, el papel de las autoridades militares $^{9}$, civiles y eclesiásticas (Lozano, 1991, p.157), y el rol de los tahúres y gariteros (Martínez, 2006, p.5). Purcell, por ejemplo, llamó la

${ }^{9}$ Pita (2007) también destacó la actitud ambivalente de algunos funcionarios neogranadinos frente a la prohibición de los juegos de azar como los virreyes, oidores, gobernadores, alcaldes y otras justicias, quienes en forma paralela al desempeño de sus funciones de gobierno administraban casas de juego (s/p). 
atención acerca de la característica agrupadora de los juegos de azar mediante el estudio de las peleas de gallos en el Chile colonial: "la revisión de las riñas de gallos correspondía a un juego concurrido no sólo por grupos populares sino también por estratos sociales más altos, lo que le da una mayor complejidad como espacio de sociabilidad" (Purcell, 2000).

Esta perspectiva ha permitido el análisis de otros actores distintos a los sectores populares. Ruigómez (2005) reconstruyó los conflictos entre los grupos de poder quiteños y el presidente de la Audiencia José de Araujo acusado de haber permitido juegos prohibidos en su casa en 1743 (pp.223240). Por su parte, Jiménez (2007) identificó algunas conexiones entre los tipos de juegos llevados a cabo en la Nueva Granada y los grupos étnicos que los practicaron. Y Whipple (2009) sostuvo que con la llegada de la independencia las nuevas autoridades quisieron fundar una decencia republicana en oposición a la idea de decencia colonial. Centró su atención en las acciones de los intendentes de policía, las resistencias de los jugadores "decentes" y los discursos a favor y en contra de las medidas publicadas en la prensa limeña (p.7).

Esta línea interpretativa de los juegos de azar llevó al estudio de los mismos como una práctica empresarial. Aunque no han abundado los estudios desde este enfoque, han predominado la revisión de las rentas producidas luego de la legalización de algunos juegos, la participación de asentistas, el desarrollo del "negocio del ocio" (Gutiérrez, 2011) y el papel de empresarios y políticos en las loterías (Lorenzo, 2014, p.174).

La temática presentó un desarrollo interesante durante la primera década del siglo XXI, al ampliar el espectro analítico y considerar los juegos de azar como actividades lúdicas y diversiones populares. Los estudios centraron su atención en el fracaso de las políticas prohibicionistas (Lima, 2016, p.7), el carácter mistificador de los juegos (Castaño, 2005) y la participación de todos los sectores sociales en ellos (Jiménez, 2007).

En posible concluir que en la historiografía de los juegos de azar han predominado los enfoques del periodo colonial. Debiéndose ello tal vez a la extensión temporal y a que las políticas prohibicionistas de mediados del siglo XVIII y comienzos del XIX hicieron pulular bandos, cédulas, decretos, leyes y juicios contra los juegos. Por otro lado, se ha prestado mayor atención a la participación de sectores bajos de la población y autoridades locales desde las fuentes antes mencionadas, produciéndose discursos 
historiográficos enfocados en los aspectos sociales, culturales y políticos de los juegos. En menor medida se ha estudiado los impactos en la economía de los mismos, tratándose tanto de los recaudos en sus aspectos positivos como de las pérdidas (fiscales) en sus aspectos negativos.

Tampoco se ha ahondado en las relaciones de poder que se construyeron alrededor de los juegos de azar. Las respuestas de los judiciables frente a las autoridades y la negociación de estas últimas con los jugadores se produjeron en un ambiente de despliegue del estado colonial y de construcción del estado republicano, lo que implicó que sus discursos manifestaran los ideales de cada uno de los grupos, cuestión a la que se presta mayor atención en este trabajo.

Algunas investigaciones han construido una visión idealista de los espacios de sociabilidad y los tipos de relaciones que allí se llevaron a cabo. Conciben a los jugadores como un grupo homogéneo, sin jerarquías, diferencias, honores y como si sus comportamientos no hubiesen generado tensiones horizontales. En ese sentido, las fuentes consultadas por estos trabajos, al ser producidas por los grupos hegemónicos, han podido permear el abordaje del objeto de estudio desde arriba y a partir de un presupuesto muy cuestionado por la historiografía que es la tesis de la "solidaridad colectiva".

En todo caso, esta historiografía de los juegos de azar es un reflejo de las políticas gubernamentales que buscaron restringir este tipo de prácticas y su desarrollo fue posible amén de la existencia de juicios, sumarios, expedientes que tanto posibilitaron a las autoridades y judiciables el acceso a la justicia, como permitieron a los historiadores el acercamiento a la cultura jurídica. En este campo, los avances de la historiografía también son notables y permiten evidenciar que, a pesar de las altas tasas de analfabetismo que se dieron especialmente en el mundo rural, los campesinos de Chile (González, 2011, pp.57-76; González, 2012a, pp. 8198), Nueva Granada (Vélez, 2013, pp.113-143, Morelli, 2016, pp. 373-396), México y el virreinato de Rio de la Plata (Barriera, 2012a, pp.41-80, Yangilevich, 2016, pp. 397-425) tuvieron acceso a la justicia, conocieron las leyes e hicieron uso de ellas, tanto de las que estaban vigentes como de la costumbre.

En este sentido se han destacado el papel que juegan los mediadores (jueces, alcaldes, curas) en el disciplinamiento social (Cordero, 2014, 
p.145), no solo como detentadores del poder coercitivo sino como negociadores (Falcón, 2010). Tanto los jueces (Cobos, 1980, p. 89) como los abogados (Palacio, 2004, pp. 261-288) han sido objeto de investigaciones historiográficas siendo estos últimos más escasos por la dificultad en encontrarlos en las fuentes (Conde, 2017, pp. 49-82; Vélez, 2008, pp. 13-51; Botero, 2010, pp.65-88). Pero ello no ha sido óbice para detectarlos ya que se ha recurrido a estrategias como de análisis de discurso (Albornoz, 2015, s/n), la identificación de la red de legos que actuaban tras bambalinas o las discusiones teóricas (Di Gresia, 2012, pp.177-212; Botero, 2013, pp. 203-220) o legislativas para modificar (modernizar) el sistema judicial mediante la introducción de jueces letrados (Bilot, 2012, pp. 99-123; Brangier, Díaz y Morong, 2018, pp.75-87).

En este escenario se ha prestado mayor atención al mundo rural y a las poblaciones alejadas de los centros administrativos y especialmente, a lo que algunos historiadores denominan como la justicia de abajo, subalterna, de primera instancia (López, Monsalvo y Suárez, 2019, pp. 113-136), de proximidad (Molina, 2010, pp. 3-23), de paz (Garavaglia, 1997, pp. 241262), pedánea (Conde, 2013, pp.35-54) de acuerdo tanto a las tradiciones jurídicas de cada territorio como al marco conceptual ${ }^{10}$.

Apoyados en este acervo historiográfico, el planteamiento sugerido permitirá el análisis de los sumarios por juegos prohibidos desde un enfoque que reconoce a los jugadores como actores jurídicos con capacidad argumentativa, a los representantes del Estado como mediadores entre el gobierno nacional y la sociedad que debían gobernar y los sumarios de policía como el guion que permite el acercamiento al juego de tensiones, relaciones y conflictos locales.

\section{Pobres e inocentes: la escasez de recursos como defensa}

Manizales era una pequeña aldea creada desde finales de la década de los años cuarenta en el extremo sur de la Provincia de Antioquia. Desde 1850 fue erigida distrito parroquial del cantón de Salamina gracias a las gestiones de sus pobladores, por lo que se creó una cárcel, escuela y un Cabildo parroquial que, acompañado del alcalde, al que se le otorgaron funciones administrativas y policiales, tuvieron a su cargo la recaudación de

\footnotetext{
${ }^{10}$ Para una discusión sobre el origen de los distintos conceptos, ver: Barriera, 2012b, pp. 50-57.
} 
impuestos, la mejora de los caminos, las sanciones administrativas y el orden de policía ${ }^{11}$.

Con poco menos de veinte mil habitantes, la parroquia se proyectaba como puerta de ingreso de las mercancías y gentes provenientes del sur y oriente del país. Muchos de estos nuevos pobladores, fueron enviados como parte de las políticas colonizadoras a partir del reclutamiento de vagos que se hicieron en otros distritos parroquiales, otros, fueron especuladores de tierras y comerciantes que avizoraron el potencial económico que ofrecía la nueva parroquia. Ello tal vez explique por qué la mayoría de los sumarios de policía de las dos primeras décadas de creación del ente territorial hayan sido contra jugadores de prohibidos y vagos (infracción vinculada muchas veces también al juego como se demostrará más adelante).

Estos sumarios fueron el resultado de los recorridos diurnos y nocturnos que debían hacer los alcaldes y comisarios por las calles de la ciudad, así como de las denuncias que presentaban los vecinos y de los interrogatorios que se derivaban de ello. Estaban compuestos por las declaraciones de testigos, la identificación del responsable, el derecho a la defensa mediante cuadernos de pruebas, la resolución y la apelación si fuere el caso frente al prefecto departamental.

Algunos contraventores recurrieron a aspectos de su condición social como la pobreza material y los malos pagos para defenderse ante la justicia, pues estos hacían parte de su cotidianidad y de sus conversaciones con vecinos, familiares y amigos. Consideramos que detrás de sus argumentaciones aparentemente graciosas y simples como pedir compasión y fingir ignorancia, existen elementos profundamente enraizados en su cultura política ${ }^{12}$.

El caso del carpintero Rafael Olarte mencionado en Monsalvo y López (2012) es un buen ejemplo de cómo algunos sujetos instrumentalizaron la noción de pobreza dentro de sus apelaciones. La situación se llevó a cabo

\footnotetext{
11"Medidas para la organización del Distrito de Manizales firmada el 23 de noviembre de 1849" (Academia Caldense de Historia, 2006, p. 352). Respecto a las funciones del cabildo ver: Giraldo (2012).

${ }^{12}$ González (2012b) considera que estas fuentes son importantes para comprender las formas de transmisión de la cultura política.
} 
el 22 de agosto de 1855 cuando Olarte solicitó el testimonio de varios vecinos que debían responder el siguiente cuestionario:

\begin{abstract}
¿Digan si sabe y les consta que siendo demasiado pobre, tengo que estar enteramente entregado al trabajo en mi profesión de carpintero sin que me sea dado consagrarme a pasatiempos perniciosos como el juego?, ¿digan si es verdad qué a causa de lo muy reducido del salario de los artesanos en este pueblo en la época actual, a un carpintero como yo, solo le alcanza lo que gana diariamente, para hacer frente a los gastos precisos de la subsistencia, sin que pueda sobrarle nada para jugar?, ¿digan si es verdad que no me han visto jugar juegos prohibidos, y qué si no lo he hecho ha sido, tal vez, a causa de la escasez de dinero? (p.121) ${ }^{13}$.
\end{abstract}

En las preguntas, bastantes dirigidas, por cierto, Olarte deja entrever el contexto de crisis económica por la que pasaba su gremio, pero no se preocupa por ocultar su pasión por el juego, que era imposible de negar frente a los vecinos que le servían de testigos. Uno de ellos aseguró enfáticamente que Olarte frecuentaba las casas de juegos y que él mismo lo había visto apostar a las cartas en la cárcel pública del distrito. Por su parte, Prudencio Orozco afirmó que cuando el carpintero no jugaba a los dados, era porque no tenía plata o se la había gastado. E Inocencio Echeverri aseveró que: "aunque es cierto que en la época actual es reducido el salario de los artesanos el exponente si es que le sobre de los gastos diarios, puesto que lo ha visto jugar"14.

Aunque la defensa no tuvo éxito porque los testigos que el propio Olarte solicitó en el cuaderno de pruebas declararon en su contra -situación que no deja de ser paradójica- por lo menos pudo obstaculizar el desarrollo del juicio y prolongar el pago de la multa hasta el último momento. En definitiva, este caso permite ver cómo las nociones asociadas a la justicia distributiva ("dar a cada uno lo que es suyo") y las diferencias estamentales heredadas

\footnotetext{
${ }^{13}$ Aunque Monsalvo y López (2012, p.121) hicieron una breve referencia a la apelación presentada por Rafael Olarte por un caso de juegos prohibidos, este artículo profundiza más en la rica información que ofrece el expediente completo. Especialmente, resalta las declaraciones de los testigos que no se tuvieron en cuenta en el trabajo previo. Se recomienda ver el expediente original: "Archivo Histórico de Manizales (de ahora en adelante AHM), fondo histórico, caja 5, libro 16, folio 355r. 22 de agosto de 1855.

${ }^{14} \mathrm{AHM}$, fondo histórico, caja 5, libro 16, folios 355r-357v. 22 de agosto de 1855.
} 
del Antiguo Régimen, aún circulaban entre los habitantes de la provincia de Antioquia, que veían en la desigualdad social un argumento útil para solicitar justicia ${ }^{15}$.

Francisco Ospina alias "el tullido" y su hermano Gaspar, recurrieron a una explicación similar cuando el alcalde Antonio Ceballos los acusó de haber jugado a los dados en compañía de otras personas dentro su propia casa. En su apelación presentada el 11 de septiembre de 1855, dijeron tener "enfermedades reumáticas que les impedía sacar por la fuerza a quien delinquiera en su hogar", y solicitaron la declaración de varios testigos que ratificaron su defensa unánimemente. En otros términos, ambos aceptaron las acusaciones, pero se escudaron en su condición de "enfermos indefensos" para beneficiarse del aparente vacío que tenía la norma en este aspecto $^{16}$.

Una de las respuestas más comunes que los jugadores dieron a los alcaldes durante los juicios, consistió en cambiar el sentido de la infracción presentándola como una tertulia de gente decente o una simple entretención donde se apostaban tabacos y monedas falsas. La razón es que una de las diferencias más importantes entre los juegos permitidos y prohibidos era el monto de las apuestas y el costo de las licencias que la policía otorgaba a quienes establecían un billar o una gallera. Es decir, el límite entre lo legal e ilegal estaba en el pago de los permisos y en las características de los objetos arriesgados.

En 1855 un par de tahúres aseguraron que el juego sucedido en su casa no había sido "un incentivo para el vicio" sino "una inocente ocupación que recrea", mediante la apuesta ficticia de tabacos y monedas de cuero. Además, expresaron que el motivo por el cual no arriesgaban dinero real era porque empeoraba la situación de "las familias en la indiferencia y la miseria, y para dar al comercio quiebras continuas"17.

En otras ocasiones, los judiciables no apelaban, pero recibían la acusación y el fallo sin ningún miramiento, por ejemplo, el alcalde Rafael Jaramillo en 1874 levantó un sumario contra Salvador Martínez (dueño de la casa de

\footnotetext{
${ }^{15}$ Sobre la pervivencia de prácticas jurídicas del antiguo régimen, ver: Fradkin (2007).

${ }^{16} \mathrm{AHM}$, fondo histórico, caja 5, libro 16, f.14v. Septiembre de 1855.

${ }^{17} \mathrm{AHM}$, fondo histórico, caja 5, libro 16, f.13v.1855.
} 
juego) y cinco personas más, por jugar tute y monte. Pero en este caso el alcalde se aseguró de descalificar el tute y centrar la atención en el juego de monte. Fueron sentenciados el primero a pagar 25 pesos de multa y todos, a 10 días de trabajo en obras públicas, que cumplieron rápidamente sin apelar, en la apertura de una calle, "empañetando la casa consistorial, arreglando las bancas y otras cosas de la escuela de niñas ${ }^{18}$.

A pesar de la escasez material, estos sujetos recurrieron a las leyes vigentes (códigos de policías) interpretándolas a su manera para demostrar la inocencia, y si no era posible, acudieron a leyes de otro tipo o más antiguas para contrarrestar las sentencias o pruebas en su contra. De igual manera, las autoridades hicieron uso de esas mismas leyes interpretándolas en clave propia, lo que demuestra que hubo una cultura legal en circulación empleada por todos los sectores implicados en los sumarios ${ }^{19}$. Incluso los prefectos que eran la segunda instancia, fungieron como garantes ante las apelaciones de unos y otros, y plantearon las interpretaciones definitivas en los debates jurídicos alrededor de los juegos prohibidos. Este será el tema del siguiente acápite.

\section{Vicios de procedimiento o interpretaciones diversas de la ley}

Aunque la profesionalización de la policía colombiana se dio a finales del siglo XIX cuando el gobierno conservador contrató a una misión francesa para su organización (Hering, 2018; Acevedo y Puentes, 2014), desde antes existía un vocabulario policial y jurídico en permanente circulación en el mundo rural. Compuesto por nociones como apelación, justicia, delito, recusación, ley natural, orden, buenas costumbres, pena, entre otras, que estuvieron presentes en las respuestas de estos hombres ante la justicia y en los fallos de los mismos alcaldes.

En el caso de los judiciales, tendieron a buscar en las leyes resquicios que permitieran crear jurisprudencia en sus casos. Para ello se valieron tanto del conocimiento de la legislación de policía como de la astucia para

\footnotetext{
${ }^{18} \mathrm{AHM}$, fondo histórico, caja 12, libro 40, f.301r.1874.

${ }^{19}$ Tanto los judiciables como los legos que apoyaban la redacción de las defensas contribuyeron a que las autoridades también legas perfeccionaran su conocimiento jurídico forjándose de esta manera una cultura jurídica. Ver: Vélez, 2008, pp. 13-51; Botero, 2010, pp. 65-88.
} 
interpretarla a su acomodo. En 1860 Álvaro Giraldo un campesino manizaleño aceptó su participación en un juego llevado a cabo en la casa de Ignacio Quintero, pero "en calidad de apostador y no de jugador", y aseveró que no había "cogido el dado para ninguna parada", y que su relación con el juego era similar a la de quien veía una pelea de gallos. Este sencillo pero confuso testimonio puso en apuros al jefe de policía, quien al notar el vacío de la ley en este aspecto, remitió el sumario al prefecto departamental, el cual concluyó que: "Álvaro Giraldo no ha infringido la disposición legal, y por cuya supuesta violación se le sometió a juicio, por tanto, se le absuelve del cargo"20.

Probablemente la falta de pericia de los alcaldes y policías, así como los intereses personales entre estos y los judiciables pudieron haber mediado en la elaboración de los sumarios y en la sentencia final. En el primer caso, muchos acusados pusieron en evidencia esta fragilidad institucional, como Francisco Ospina que fue sentenciado por la alcaldía a pagar veinte pesos de multa por haber reincidido en la práctica de un juego de cartas denominado monte. Su apelación se basó en cuestionar el procedimiento judicial: "la declaración de un solo testigo tan solo sirve para abrir una averiguación sumarial pero no para sentenciar a un hombre que tan solo ha sido mencionado". Posteriormente, Ospina solicitó la revisión de los archivos de la alcaldía para demostrar que había sido exonerado de la primera causa que le atribuían y que, por tanto, la acusación de reincidente no era comprobable ${ }^{21}$. Al final del expediente el prefecto le concedió la razón sin dar mayores explicaciones, cuestión que evidencia fallas en el archivamiento del primer caso o en la aplicación de la segunda sentencia.

Ignacio Quintero, jugador mencionado anteriormente, solicitó una rebaja en la pena que le habían impuesto por tahúr. El debate fue muy interesante debido a que él consideraba que las "leyes prohibían llevar dos investigaciones simultáneas contra la misma persona así hubiera cometido varios delitos", y por este motivo solicitó "unificar ambos sumarios en un solo expediente". Su intención era realmente muy evidente, ya que, si el alcalde accedía a su petición de juzgarlo solo por vagancia, no tenía que pagar la multa en moneda sonante que se le exigía como jugador ${ }^{22}$.

\footnotetext{
${ }^{20} \mathrm{AHM}$, fondo histórico, caja 5, libro 16, f.182v.1860.

${ }^{21} \mathrm{AHM}$, fondo histórico, caja 5, libro 16, f.186v.1860.

${ }^{22} \mathrm{AHM}$, fondo histórico, caja 5, libro 16, f.317r.1865.
} 
Aunque la defensa de Quintero parecía ser coherente, el alcalde Jaramillo rechazó su solicitud el 19 de agosto de 1865, con el argumento de que: "bien pudiera acumularse este juicio al que se le sigue al representante por vagancia, pero este se encuentra ya sentenciado, y por consiguiente no hay lugar a su acumulación"23. Quintero no se conformó con el fallo y envió el caso a segunda instancia, donde el prefecto le otorgó una reducción de la pena de los cincuenta a los veinte pesos pero no la combinación de los expedientes. A diferencia del alcalde, el prefecto, consideró que no existían "suficientes evidencias para comprobar su reincidencia" 24.

Lo interesante de este sumario es que nuevamente fueron cuestionadas las habilidades del alcalde para aplicar la norma y recopilar las pruebas relacionadas con la culpabilidad del sindicado. Si bien Quintero no logró su objetivo de unir los dos expedientes, sí dejó en evidencia las falencias del procedimiento legal. Una muestra más de que los actores sociales no fueron simples espectadores del teatro del poder y que utilizaron recursos legales que iban más allá del sentido común, situación que evidencia la existencia y circulación de un conocimiento jurídico con el propósito de defenderse. Probablemente experiencias anteriores habían sido la razón de la construcción de esta cultura legal, lo que no es óbice para pensar que su apropiación haya tenido otros efectos en la relación de estos actores con el Estado25.

A pesar de que lo argumentado hasta ahora demostraría que entre los judiciables por juegos prohibidos en Manizales, durante las dos primeras décadas de existencia jurídica de la parroquia, hubo una cultura legal establecida y difundida, en ocasiones la ignorancia de las leyes fue un argumento utilizado en las defensas jurídicas para escapar a la justicia, aunque con poco éxito. Se recurrió a demostrar el origen humilde de los sujetos, el buen comportamiento anterior y el desconocimiento de que sus actos fueran imputables, paradójicamente al tiempo que buscaban en los resquicios de la misma ley otras formas de escabullirse.

\footnotetext{
${ }^{23} \mathrm{AHM}$, fondo histórico, caja 5, libro 16, f.317v.1865.

${ }^{24} \mathrm{AHM}$, fondo histórico, caja 5, libro 16, f.317r.1865.

${ }^{25}$ Infortunadamente solo hemos encontrado un expediente en el que el defensor firmara, pero son evidentes las manos legas en varios expedientes aquí citados.
} 
Fulgencio Valencia y seis personas más fueron juzgados por jugar tute con cartas en varias tiendas del pueblo ${ }^{26}$. Uno de ellos nombró un defensor que se encargó de dirigir un cuestionario en el que se interrogaba a distintos testigos acerca de cómo se denominaba el juego en el que estos participaron y qué tipo de apuestas vieron. La idea era demostrar que se trataba del "tute" y que estaban apostando tabacos. Al parecer estaban seguros de que este juego tolerado durante las fiestas patrias del 20 de julio por las autoridades no estaba prohibido y de hecho así lo ratificaron la mayoría de testigos.

El tute fue presentado como un juego donde obra la inteligencia y no la suerte "como en los de dado, treinta y una, pasadiez y otros". La razón de este argumento era que diversos testigos identificaron la casa de Feliz Ramírez como el lugar de juegos, por lo que ante esta evidencia era importante demostrar que:

1. No era un juego de azar para lo cual se requerían permisos de la alcaldía

2. Que se jugó con intervalos de más de 8 días y

3. Quienes jugaron no pagaron garita sino alumbrado y naipes.

El jefe municipal reconoció que el juego de tute y otros no comprendidos en el artículo 82 de la ley 213 eran permitidos por la policía, pero siempre que se pagaran los derechos correspondientes a la Corporación Municipal, de acuerdo con lo prescrito en el artículo 90 de la mencionada ley. Como los sindicados no cumplieron con este deber, se les calificó la falta de muy leve, y se los condenó a pagar una multa de cinco pesos a cada uno de ellos.

A pesar de que la multa no fue alta, el defensor de Justo Gálvez, el abogado Alejandro Restrepo $\mathrm{R}$, apeló la sentencia ante el prefecto en tres sentidos: en el primero se intentó ratificar que había sido un "pasatiempo", donde no medió ningún interés económico. En el segundo, que su defendido y compinches eran "campesinos, trabajadores y honrados, cuya ignorancia es conocida de todo el mundo; y otros, como mi defendido, aunque viven en el lugar, carecen absolutamente de conocimientos en materia de legislación". Es decir, la ignorancia de la ley fue la salida jurídica para demostrar que no hubo "malicia ni voluntad de cometer la falta". El problema era que estos argumentos hundían más a sus defendidos ya que ratificaban la comisión

${ }^{26} \mathrm{AHM}$, fondo histórico, caja 12, libro 40, f.407r. octubre de 1872. 
de la misma "a plena luz del día", pero restándole importancia por la nimiedad de lo jugado al tute de "uno o dos cigarros", que "no son suficientes para que el ganador saque un provecho o utilidad que lo induzcan a interesarse para ganar la partida"27.

$Y$ en el tercer argumento, se buscó demostrar que el tute era concebido como un juego inocente que podía tener lugar en cualquiera parte, es decir, que era legal: "Todo el mundo ha creído que esto es así, y cuando se efectuó el juego se hizo bajo la persuasión que con ese hecho no se cometía delito, ni se defraudaban derechos del distrito". Con estos argumentos se buscaba que no se los castigara porque no había interés, es decir apuestas en el juego.

Finalmente, solicitó que se derogara la multa a su defendido y amigos de juego advirtiendo los peligros morales que recaen sobre los jugadores y que ellos, en lo sucesivo, no volverían a jugar:

Y aplaudo el celo del Sr. Jefe Municipal, y conozco que este es el verdadero medio de moralizar la sociedad y destruir toda ocupación que no sea en provecho individual o social: que el hombre no sabe ocuparse en ningún juego, ni aún por pasatiempos, y que el tiempo debe invertirse de otra manera más útili ${ }^{28}$.

Dos semanas después obtuvieron la respuesta desde Salamina por parte de Marco Aurelio Arango, prefecto departamental. Este empezó conminando al alcalde de Manizales a que por más "patriótico" y digno de alabanza que fuera su "espíritu moralizador" no podía interpretar tan laxamente la legislación. $Y$ les dio la razón a los querellantes en cuanto a que el tute no estaba en la lista de juegos prohibidos por lo que no podían ser castigados por jugarlo.

Monsalvo y Bedoya (2014) mostraron en su investigación las dificultades de la administración local para el reclutamiento de una burocracia capacitada para ejercer las funciones, por lo cual, la administración recurrió a personas analfabetas o con escaso conocimiento del Estado. Sin embargo, al estudiar las elaboraciones administrativas llevadas a cabo por estos funcionarios se observa un conocimiento de la norma, $y$, aunque hemos presentado algunas

${ }^{27} \mathrm{AHM}$, fondo histórico, caja 12, libro 40, f.433r. octubre de 1872.

${ }^{28} \mathrm{AHM}$, fondo histórico, caja 12, libro 40, f.434r. octubre de 1872. 
fallas como los errores de interpretación o el desconocimiento de las mismas, no siempre se dieron por la falta de formación sino también por los intereses que estos mismos pusieron en juego al juzgar a sus convecinos.

\section{De la justicia a las justicias}

Como se mostró en el anterior acápite los jugadores de prohibidos tuvieron el conocimiento jurídico para defenderse frente a la justicia local, pero también la astucia para buscar en los entresijos de la legislación una interpretación que favoreciera su inocencia. En ocasiones, estos recursos contaron con la fragilidad institucional de un jefe municipal con poco conocimiento y capacidad para contra argumentar, o para no cometer errores en el procedimiento; en otras, estos funcionarios actuaron con conocimiento y precisión, de tal manera que no pudieron revertir sus sentencias.

Ambos escenarios recrean la imagen de la circulación de leyes, o cómo fueron aprehendidas y empleadas cuando lo requirieron tanto los judiciables de prohibidos como las autoridades. $Y$ aunque las defensas de los jugadores debían ceñirse a los códigos de policía, los sumarios correccionales por juegos prohibidos demuestran que la cultura legal fue más allá y exploraron en distintos documentos del pasado soluciones a sus problemas jurídicos, cuando no, recurrieron a laxas interpretaciones de cualquier tipo de ley.

En 1865 un comerciante llamado Antonio María Tobón fue juzgado por apostar a los dados y multado con 10 pesos (Monsalvo y López, 2014, pp.113-130). En su defensa, el acusado pidió que todos los funcionarios fueran sus testigos y luego procedió a recusarlos. El argumento de Tobón se basó en una ley de procedimiento criminal que aparecía en la recopilación granadina, y aunque esta se refería a los jueces que eran testigos de un hecho y no a los alcaldes, para Tobón era lo mismo porque ambos aplicaban justicia. Pero para el alcalde, ello significaba que, si en el ejercicio de sus funciones veía y capturaba a un delincuente, este lo podía solicitar como testigo para impugnar su juicio: "Semejante condescendencia 
en el Juez, sería nada menos que coadyuvar a la impunidad que el reo pretende" advirtió el alcalde ${ }^{29}$.

El uso de leyes de procedimiento criminal que se aplicaban en la justicia ordinaria fue uno de los recursos empleados por los jugadores de prohibidos. Ello no significó el desconocimiento de los códigos de policía, sino que fue la alternativa cuando estos no eran útiles en la defensa y como una manera de extender, dilatar o en enmarañar su proceso. Pero también implicó un conocimiento de normas y leyes más generales que pudieron circular en la comunidad gracias a personajes como el descrito Tobón, que mezclaba sus negocios inmobiliarios con los enredos judiciales y probablemente compartía la información con sus compinches de juego.

Pero las leyes no fueron usadas convenientemente solo por los jugadores de prohibidos, también las autoridades recurrieron a este juego para interpretar las normas. El prefecto de Salamina consultado por el alcalde de Manizales acerca de unos jugadores que apostaron al tute respondió con un interesante consejo para el jefe municipal. El problema planteado era la definición de "juego prohibido". El artículo 82 de la ley 213 de 1856 definió los juegos prohibidos como aquellos "en que la inteligencia y el saber del jugador no puedan inclinar la suerte a su favor" y mencionó que eran los juegos de: Dados, monte, ruleta, primera, veintiuna, treinta y una, cachimona, pasa diez, ladrillo, el orito". Ahora, ¿qué pasaba cuando se jugaba otra cosa que no estaba en este listado? El parágrafo único de este artículo estableció que cuando se quería jugar algo que no aparecía en este listado, los jefes de policía debían reconocer y calificar como prohibido o permitido. Pero la misma ley no explicó con base en qué criterios, solo que podían consultar con dos vecinos del lugar.

Para el prefecto, y aquí viene el consejo para el jefe municipal, debían valerse del listado de juegos más amplio que aparecía en la recopilación castellana, es decir, en unas leyes antiguas. Este recurso complementario de una ley republicana con otra de Castilla recopilada en el libro 8으, es decir, el de lo penal en 1484, hace referencia a un uso indiferenciado de las justicias por parte de las autoridades en la década de 1870 en una ciudad que no tuvo pasado colonial. La justicia antigua aquí aparece como complemento de la nueva -que quizá por esto estaba en construcción- y no como oponente.

${ }^{29} \mathrm{AHM}$, fondo Histórico, caja 5, libro 16. f.437v.1865. 
Con ello el alcalde debió caracterizar este juego como permitido, por lo que no podía aplicársele el artículo 82 a los implicados, sino el 90 que hacía referencia a las casas particulares utilizadas para juegos permitidos. Ante esta falla la sentencia no era válida:

La policía, si lo cree conveniente, puede emplear medios indirectos de persecución contras los que quieran establecer casas de juegos permitidos, a la sombra del art. 91 de la citada ley; pero en opinión de la Prefectura no pueden adoptar medidas como las de qué trata este procedimiento $^{30}$.

En conclusión, la falla que encontraron y permitió a estos judiciables escapar de la justicia, fue el uso incorrecto de la ley por parte del alcalde, lo cual destruyó todo el proceso. Aunque la falta efectivamente fue cometida y debió ser castigada, como lo señaló el prefecto.

Algo similar ocurrió cuando el alcalde Rafael Jaramillo Uribe impidió que los acusados apelaran su sentencia porque les exigió los gastos de copias y envío del sumario a Salamina, con base en el artículo 807 del código judicial ${ }^{31}$. En este caso los acusados debieron solicitar al jefe municipal que aplicara el código de policía, que garantizaba la gratuidad en las apelaciones en los casos de justicia correccional, a lo que debió transigir el alcalde luego de la recomendación del prefecto.

Aunque pudo haberse tratado de una equivocación del alcalde, llama la atención que sus funciones se ceñían al mantenimiento del orden de policía mediante la aplicación del código de este ramo y no a la justicia ordinaria. Es probable que el mal uso de este haya sido un acto consciente, mediado por sus relaciones con los acusados. Todo ello evidencia no solo un conocimiento sino una capacidad en el uso de las leyes, incluso cuando estas no correspondían.

Los hermanos Ospina sostuvieron un largo debate con el alcalde por su acusación de juegos prohibidos. Intentaron defenderse de distintas maneras hasta que recurrieron a comparar las leyes de policía con las cuales estaban siendo juzgados, con otras normas que las pudiera contrarrestar ${ }^{32}$.

\footnotetext{
${ }^{30} \mathrm{AHM}$, fondo histórico, caja 12, libro 40, f.407r. octubre de 1872.

${ }^{31} \mathrm{AHM}$, fondo histórico, caja 59, libro 18, f.11r. abril 8 de 1873.

${ }^{32} \mathrm{AHM}$, fondo histórico, caja 5, libro 16, f.13v.1855.
} 
En este caso optaron por el código penal y citaron los artículos 413 y 414 de dicha ley para rebatir la utilización del verbo "tener" en la acusación que el jefe municipal les hizo ${ }^{33}$. Aunque en esta declaración pueden observarse términos que no eran muy comunes en el vocabulario campesino de la época como "prueba irrefragable" y "sentido de la ley", es muy probable que el abogado o el procurador se los haya explicado. De todos modos, llama la atención que en algunas investigaciones realizadas por los alcaldes en otros sumarios existan términos similares, lo que comprueba la permanente circulación del lenguaje jurídico entre los actores estatales y sociales.

En otros casos, hubo coincidencias en las leyes aplicadas por las autoridades y las utilizadas por los judiciables para defenderse, pero la interpretación de unos y otros fue distinta. En ello jugó un papel importante la astucia de los jugadores para crear una jurisprudencia sobre lo que ellos consideraban una interpretación literal del código de policía. Valga el siguiente ejemplo para demostrar lo dicho.

En 1874 el alcalde de Manizales abrió un juicio sumarial contra Bartolomé Marulanda, Jesús Vallejo (guardas de la renta de licores), Cecilio Grisales (agricultor) y Andrés Agudelo por juegos prohibidos, y los sentenció a diez días de trabajo en obras públicas. Ante ello, los sujetos apelaron la decisión municipal porque consideraban que el alcalde interpretaba mal el código de policía, ya que:

El artículo 83 de la ley citada dice: Todo el que jugare a cualesquiera de los juegos expresados será castigado con tales y tales penas. Nosotros jugamos monte y tute y se nos debería castigar según la disposición citada si no fuera que hay una circunstancia en que el Señor alcalde no se ha fijado (...) y es que nosotros no jugamos plata y no jugando plata no hay delito ${ }^{34}$.

El conocimiento de la norma hacía parte de la cultura legal de la época, además del hecho de que dos de los encausados eran empleados públicos

${ }^{33} \mathrm{AHM}$, fondo histórico, caja 5, libro 16 , f.14v.1855

${ }^{34} \mathrm{AHM}$, fondo histórico, caja 17, libro 57, f.9r.1874. 
que probablemente tuvieron acceso a un defensor lego que ayudó a la redacción de la carta ${ }^{35}$.

Era claro que no ocultaban la práctica del juego e incluso que habían apostado. Lo que discutían era que la apuesta no era en dinero ¿qué diferencia existía en este caso? Para los jugadores, su interpretación del artículo 89 era que al ser explícita su declaración en cuanto a que debía decomisarse "todo el dinero que se encuentre en los juegos prohibidos" y en su juego no hubo dinero, entonces no había delito. Porque para ellos, la ley tenía por objeto castigar a los que apostaran dinero, pero de "ninguna manera el juego de monte por pura diversión"36.

La diferencia que plantearon entre apuesta y diversión apuntaba a una exégesis de la ley de policía, ya que de acuerdo a ellos si se hubiera pensado en castigar la diversión que generaba el juego, la ley hubiera explícitamente utilizado la palabra "interés" en vez de "dinero". Por lo que finalizaron planteando interrogantes que cuestionaban el accionar del jefe municipal:

¿Sería delito jugar monte sin apostar nada, valor ninguno? Según Ud. sí, pero según la ley no. Y de paso hacemos observar a Ud. que cuando la ley es terminante ni el Tribunal mismo tiene derecho para interpretarla ${ }^{37}$.

Contundentes palabras que hablan no solo de un conocimiento de la ley y de su uso sino del ladino detalle de que la ley no estaba sujeta a interpretación y que su aplicación debía ser literal. Pero, como en las declaraciones de los testigos y de ellos mismos habían manifestado que se había apostado "un real de pan de queso", solicitaron que esto se entendiera como "ocho roscas de dicho pan". Es decir, no era el dinero, sino el valor del producto con lo que ratificaban que era una ocupación inocente.

${ }^{35}$ Palacio (2004) llamó la atención acerca de los secretarios de juzgados que luego de unos años de experiencia en la administración de justicia se dedicaban a ser defensores (p.283).

${ }^{36} \mathrm{AHM}$, fondo histórico, caja 17, libro 57, f.9r.1874.

${ }^{37} \mathrm{AHM}$, fondo histórico, caja 17, libro 57, f.9r-9v. 
Finalmente, la prefectura no aceptó los argumentos de estos y ratificó la sentencia del jefe municipal. Según el prefecto si la ley perseguía los juegos prohibidos era porque:

A sus ojos, lo mismo es que se juegue dinero que cualquiera otra cosa que tenga un valor convencional y positivo (...) La ley no mide la suma de los valores, ni su naturaleza intrínseca ni la sustancia de que se compongan, ni la manera como [ilegible] en los cambios sociales para prohibir el juego y castigar a los jugadores. (...) Tan culpable es el que juega una casa o un tabaco o una moneda de plata, con la diferencia que la plata se decomisa como multa en los casos del artículo 89 de la citada ley. Pero aun prescindiendo de estas jurídicas demostraciones debe tenerse en cuenta, como razón concluyente, que el artículo 83 de la misma ley, castiga a los jugadores de juegos prohibidos, sin establecer distinciones de ninguna especia, y abstracción hecha de la calidad de los valores que se hayan apostado al juego ${ }^{38}$.

El prefecto no les dio la razón en cuanto a que el juego de monte estaba prohibido y a que apostar objetos sí representaba una violación del código de policía. Este recurso de apostar panes, tabacos u otros objetos que tenían un precio en el mercado pareció ser parte de la astucia de los jugadores, con la que pretendieron no ser castigados, en este caso claramente no funcionó la estrategia.

\section{Conclusión}

En el trabajo mostramos que la principal preocupación de los alcaldes y jefes de policía durante las dos primeras décadas de creación de la parroquia de Manizales estuvo vinculada a erradicar la presencia de jugadores de prohibidos y vagos. Ello se debió a la llegada de personajes con estos antecedentes que eran enviados a poblar, pero también a la dinámica misma de la vida cotidiana en un poblado nuevo. De esta manera, se pretendió evitar afecciones económicas, familiares y morales. En este proceso, los alcaldes parroquiales debieron entrometerse en las actividades cotidianas y de ocio que realizaban los parroquianos, lo cual, les generó no pocos conflictos con sus convecinos.

También hemos identificado a los tahúres como orientadores de las apuestas en los juegos y profesionales en los mismos. Aunque jugadores y

${ }^{38} \mathrm{AHM}$, fondo histórico, caja 17 , libro 57, f. $15 \mathrm{v}$. 
tahúres compartían el gusto por el juego, probablemente se diferenciaban en las capacidades económicas de unos y otros. A pesar de ello, como lo hemos planteado en otras ocasiones, ambos se caracterizaron por no ser actores de reparto en la construcción de la autoridad local y reaccionaron frente a la intromisión de la policía por medio de discursos y prácticas que los llevaron a defenderse.

El hecho de encontrarnos en los sumarios a campesinos, muchos de ellos analfabetos que citaban códigos de policía, leyes, manuales de procedimientos es no solo la evidencia de la circulación de una cultura jurídica entre estos sectores bajos de la población, sino el acceso y uso de la justicia; no como un ideal teórico de los gobiernos liberales, sino como una realidad fáctica en la vida cotidiana. De esta manera, estos campesinos contribuyeron en medio de las necesidades creadas por sus "vicios" a la construcción del Estado, ya que impulsaron a las autoridades locales a conocer más y mejor las normatividades, a formar un grupo de defensores legos y a la circulación de información jurídica.

Así, usaron estrategias jurídicas como la apelación para llevar ante la autoridad departamental sus casos, mostrando los malos procedimientos jurídicos del alcalde de turno o justificando su accionar por la pobreza material. De igual forma, cuando no fue posible demostrar la inocencia, recurrieron a argumentos basados en la enfermedad o incapacidad para evadir el pago de la multa correspondiente. Finalmente, algunos hicieron uso de una concepción antigua de justicia para clamar "por lo justo", lo que ellos parecían merecer.

Estas tres tipologías de respuestas evidencian un conocimiento de las normas jurídicas probablemente basado en la trayectoria transgresora de los mismos personajes al tiempo que demuestra la existencia de una cultura legal en el mundo rural antioqueño. Queda por fuera del análisis, la presencia de legos que representaban o redactaban las defensas de los jugadores, algunos de ellos tahúres reconocidos y exfuncionarios que adquirieron experticia en un área específica. Sería interesante analizar cómo se construyeron y mantuvieron estas redes de solidaridad o si fueron un negocio lucrativo como en otros lugares de América. 


\section{Bibliografía}

Academia Caldense de Historia. (2006). Archivo Historial. Vol.3 [1923]. Imprenta Departamental.

Acevedo, A. y Puentes, M. (2014). Orden y autoridad en los orígenes del proyecto político de la regeneración (1885-1899). La creación del primer cuerpo de Policía Nacional en Bogotá. Historia y Espacio, (42) pp.163-183.

Albornoz, M. (2015). Autoridades locales conflictuadas: temores y dificultades de jueces territoriales en Chile colonial (1711-1817). Nuevo Mundo, Mundos Nuevos, https://doi.org/10.4000/nuevomundo.68292

Ansolabehere, K. (2011-2012). Cultura legal, Eunomía. Revista en cultura de la legalidad, (1), pp.133-140.

Barriera, D. (2012a). Culturas jurídicas, poder político y autoridad en un pueblo del Río de la Plata al calor de la Revolución de Mayo. Revista SudHistoria (5), pp. 41-80.

Barriera, D. (2012b). Justicia de proximidad: pasado y presente, entre la historia y el derecho. PolHis, (10), pp.50-57. Recuperado de http://www.historiapolitica.com/datos/boletin/Polhis10_BARRIERA.pdf

Becerra, D. (2010). Historia de la policía y del ejercicio del control social en Colombia. Prolegómenos. Derechos y Valores, (25), pp.143-162.

Bilot, P. (2012). Las causas por torcida administración de justicia: mirada letrada hacia prácticas legas en Chile, 1824-1875. SudHistoria, (5), pp. 99-123.

Bohoslavsky, E. y Di Liscia, M. (2005), Instituciones y formas de control social en América Latina 1840-1940. Prometeo Libros-Universidad Nacional de General Sarmiento-Universidad Nacional de la Pampa.

Botero, A. (2010). La tensión entre la justicia lega y la justicia letrada durante la primera mitad del siglo XIX. El caso de Antioquia (Nueva Granada). Investigaciones, (7), pp. 65-88.

Botero, A. (2013). La ley y el código en las constituciones provinciales independentistas de la Nueva Granada: ¿Para qué más? Revista Prolegómenos-Derechos y Valores, II, pp. 203-220. https://doi.org/10.18359/dere.770 
Brangier, V.; Díaz, A. y Morong, G. (2018). Acusaciones contra jueces legos ante jueces de Letras: uso social del avance de la justicia letrada. Zona centro-sur de Chile, 1824-1875. Historia Unisina, 1 (22), pp.7587. Recuperado http://revistas.unisinos.br/index.php/historia/article/view/htu.2018.221.0 6

Cabrera, M.A. (2001). Historia, lenguaje y teoría de la sociedad. Ediciones Cátedra.

Caillois, R. (1997). Los juegos y los hombres. La máscara y el vértigo. Fondo de Cultura Económica.

Castaño, Y. (2005). Rinden culto a Baco, Venus y Cupido: Juegos y actividades lúdicas en la Provincia de Antioquia y otras zonas neogranadinas, siglos XVII-XVIII. Historia Crítica, (30), pp.115-138.

Cecchi, A. (2010). Esfera pública y juegos de azar: del meeting contra el juego al allanamiento de domicilio privado. Prensa, parlamento y policía en Buenos Aires (1901-1902). Cuaderno de Antropología Social, (32), pp.169-194.

Charaudeau, P. y Maingueneau, D. (2005). Diccionario de análisis del discurso. Amorrortu.

Cobos, M. (1980). La institución del juez de campo en el Reino de Chile durante el siglo XVIII. Revista de Estudios Histórico Jurídicos, (5), pp.85-165.

Conde, J. (2013). La administración de justicia en las sociedades rurales del Nuevo Reino de Granada, 1739-1803. Historia Crítica, (49), pp.35-54. https://doi.org/10.7440/histcrit49.2013.03

Conde, J. (2017). Tumultos, cultura jurídico-política y sociedad rural en el sitio de Chinú. Nuevo Reino de Granada 1798-1813. Actas del V Congreso latino-americano de historia económica (CLADHE V). São Paulo, Brasil (pp. 49-82). Universidade de São Paulo.

Cordero, M. (2014). Precariedad del proyecto disicplinador de la corona e iglesia en el siglo XVIII: Las doctrinas periféricas de la diócesis de Santiago de Chile. En G. Undurraga. Formas de control $y$ disciplinamiento. Chile, América y Europa, siglos XVI-XIX (pp.143166). Ril Editores 
Di Gresia, L. A. (2012). Miradas letradas sobre instituciones legas. Las críticas y propuestas de los tesistas en jurisprudencia para la reforma de la justicia de paz de la provincia de Buenos Aires (segunda mitad de siglo XIX). SudHistoria, (5), pp.177-212.

Falcón, R. (2010). Jamás se nos ha oído en justicia...disputas plebeyas frente al Estado nacional en la segunda mitad del siglo XIX. En A. Escobar, R. Falcón, \& R. Buve, La arquitectura histórica del poder. Naciones, nacionalismos y Estados en América Latina. Siglos XVIII,XIX y XX. (pp.255-276). El Colegio de México.

Falcón, R. (2015). El Jefe Político: un dominio negociado en el mundo rural del Estado de México, 1856-1911. El Colegio de México-El Colegio de Michoacán.

Fradkin, R. (2007). El poder y la vara. Estudios sobre la justicia y la construcción del Estado en el Buenos Aires rural. Prometeo Libros.

Garavaglia, J. (1997). Paz, orden y trabajo en la campana: la justicia rural y los juzgados de paz en Buenos Aires, 1830-1852. Desarrollo Económico, 37 (146), pp.241-262.

Giraldo, L.F. (2012). Redes familiares y político-clientelares en Manizales (Colombia) 1850-1930. Tesis de doctorado inédita. Universidad de Salamanca, España.

González, C. (2011). Para que mi justicia no perezca. Esclavos y cultura judicial en Santiago de Chile, segunda mitad del siglo XVIII. En M. P. Polimene, Autoridades y prácticas judiciales en el Antiguo Régimen. Problemas jurisdiccionales en el Río de la Plata, (pp. 57-75). Prohistoria.

González, C. (2012a). El abogado y el procurador de pobres: la representación de esclavos y esclavas a fines de la colonia y principios de la República. SudHistoria, (5), pp.81-98. Recuperado de http://repositorio.uchile.cl/handle/2250/170529

González, C. (2012b). Las posibilidades del registro judicial para rastrear la recepción de saberes sobre justicia y gobierno. Nuevo Mundos, Mundos Nuevos, (20). https://doi.org/10.4000/nuevomundo.62418

Gutiérrez, A. (2011) El negocio del ocio en el siglo XVIII. El caso de Don Juan Sánchez Casahonda. Editorial Académica Española. 
Hering, Max S. (2018).1892: un año insignificante. Orden policial y desorden social en la Bogotá de fin de siglo. Editorial Planeta.

Huizinga, J. (2000). Homo Ludens. Alianza-Emecé.

Jiménez, O. (2007). El frenesí del vulgo. Fiestas, juegos y bailes en la sociedad colonial. Universidad de Antioquia.

Joseph, G. y Nugent, N. (1994). Aspectos cotidianos de la formación del estado. La revolución y la negociación del mando en el México moderno. Ediciones Era.

Lima, M.A. (2016). Paixão arraigada no peito os jogos de azar no cotidiano fortalezense (1922-1930). Luminaria Academica.

López, H., Monsalvo, E., y Suárez, M. (2019). De niño a delincuente: los menores infractores en la mira de la justicia local, Manizales (Colombia), 1859-1897. En L. Alarcón. Colombia: historia, educación y política. Miradas múltiples (pp. 113-136). Universidad del Atlántico.

Lorenzo, M.D. (2014). De juego prohibido a negocio afortunado. Empresarios y políticos hacia una gestión pública de las loterías en México, 1915-1933, Tzinzun. Revista de Estudios Históricos, (60), pp.170-203.

Lozano, T. (1991). Los juegos de azar. ¿Una pasión novohispana? Legislación sobre juegos prohibidos en Nueva España siglo XVIII. Estudios de Historia Novohispana, 11 (11), pp. 155-181.

Martínez, M. (2006). De público jugador a oculto garitero: El juego de azar en Chile o la historia de un oficio prohibido. Universidad de Chile.

Miranda, J. (1962). Humboldt y México. Universidad Nacional Autónoma de México.

Molina, E. (2010). Los funcionarios subalternos de justicia en Mendoza, 1820-1852: entre el control comunitario y el disciplinamiento social. Nuevo Mundo Mundos Nuevos, (23). https://doi.org/10.4000/nuevomundo.59353.

Monsalvo, E. y Bedoya, A. (2014). El complejo establecimiento del orden de policía en una sociedad de frontera. Manizales 1853-1871. Revista Virajes, (16) 2, pp.41-65.

Monsalvo, E. y López, H. (2014). La acción policial en un territorio periférico. La justicia en la parroquia de Manizales.1855-1865. Memoria y 
Sociedad, (18), pp.113-130. https://doi.org/10.11144/Javeriana.mys1837.aptp

Morelli, F. (2016). Esclavos alcaldes y municipios. La justicia local en una región de frontera. En E. Caselli. Justicias, agentes y jurísdicciones. De la monarquía hispánica a los Estados nacionales (España, América, siglos XVI-XIX), (pp. 373-396). Fondo de Cultura Económica de México.

MorillaS, C. (1990). Huizinga-Caillois: Variaciones sobre una visión antropológica del juego. Enrahonar, (16), pp.11-39.

Nieto, J. (2004). Sobre el discurso histórico y el discurso literario. Anuario de Historia Regional y de las Fronteras, (9), pp.175-202.

Palacio, J. M. (2004). "Aves negras": Abogados rurales y la experiencia de la ley en la region pampeana, 1890-1945. Desarrollo Económico, 44 (174), pp. 261-288.

Pereira, E. (1947). Juegos y alegrías coloniales en Chile. Editorial Zig-Zag.

Pita, R. (2007). La afición de funcionarios, militares y religiosos a los juegos de azar: Entre la transgresión y el buen ejemplo. Revista Credencial Historia, (215),

$\mathrm{s} / \mathrm{p}$.

Recuperado

de: https://www.banrepcultural.org/biblioteca-virtual/credencialhistoria/numero-215/entre-la-trasgresion-y-el-buen-ejemplo.

Purcell, F. (2000). Diversiones y juegos populares. Formas de sociabilidad y crítica social. Colchagua, 1850-1880. LOM Ediciones.

Ruigómez, C. (2005). Conflictos entre los grupos de poder quiteños en torno a los juegos de azar (1737-1747). Estudios Humanísticos, (4), pp.223240.

Vargas, J. (1990). La Sociedad de Santa Fe Colonial. Centro de investigación y educación popular CINEP.

Vélez, J. (2008). Abogados, Pescribanos, rábulas y tinterillos. Conflictos por la práctica del derecho en Antioquia, 1821-1843. Estudios Políticos, (32), pp.13-51.

Vélez, J. (2010). Contra el juego y la embriaguez. Control social en la Provincia de Antioquia en la primera mitad del siglo XIX. En Todos somos Historia. Tomo 3. Control e Instituciones, (pp. 59-77). Editorial Universidad de Medellín, 
Vélez, J. (2013). El establecimiento local de la administración de justicia en Antioquia, 1821-1853. El difícil cumplimiento de una promesa republicana. Anuario Colombiano de Historia Social y de la Cultura, 40 (1), pp.113-143.

Viqueira, J. P. (1987). ¿Relajados o reprimidos? Diversiones públicas y vida social en la ciudad de México durante el Siglo de las Luces. Fondo de Cultura Económica.

Whipple, P. (2009). ¿Apostando por la república? Decencia, apuestas e institucionalidad republicana durante la primera mitad del siglo XIX en Lima. A Contra Corriente: una revista de historia social y literatura de América Latina. 6 (3), pp.1-35.

Yangilevich, M. (2016). Administración de justicia, derechos, gobierno y practicas judiciales en la construcción estatal (Buenos Aires, 18211886). En E. Castelli. Justicia, agentes y jurísdicciones. De la monarquía hispánica a los estados nacionales (España y América, siglos XVI-XIX) (pp. 397-425). Fondo de Cultura Económica. 